\title{
AULAS VIRTUALIZADAS NO ENSINO SUPERIOR: Ainda Precisamos do Corpo para Ensinar e Aprender?
}

\author{
Derli Juliano Neuenfeldt ${ }^{1}$ \\ Rogério José Schuck ${ }^{2}$ \\ Isabel Pavan ${ }^{3}$
}

\begin{abstract}
RESUMO
Esta pesquisa qualitativa investigou o lugar do corpo no Ensino Superior, a partir da análise do discurso de estudantes e professores de Graduação que, em 2020, experimentaram aulas virtualizadas no período da pandemia de Covid-19. O contexto de estudo foi uma instituição de Ensino Superior do RS/Brasil. As informações foram coletadas com 245 estudantes e 40 professores, por meio de um questionário elaborado no Google Forms. Em relação ao lugar do corpo nas aulas da Graduação, constataram-se compreensões diferentes, que transitam entre a possibilidade de renúncia ao encontro físico e presencial, como no caso do ensino dos conhecimentos teóricos, e as que reclamam da ausência corporal, principalmente em se tratando do conhecimento construído em aulas práticas, nos laboratórios de ensino e na interação entre estudantes e professores. Conclui-se que ainda há lugar para o corpo no Ensino Superior e que aprendemos na relação com o outro e por meio dos sentidos corporais. Negar o corpo é colocar-se na contramão da essência da existência humana, pois somos corpo e nos fazemos presentes no mundo a partir dele.
\end{abstract}

Palavras-chave: Ensino; corpo; ensino superior; tecnologias digitais.

\section{VIRTUALIZED CLASSES IN HIGHER EDUCATION: DO WE STILL NEED THE BODY TO TEACH AND LEARN?}

\section{ABSTRACT}

This qualitative research investigated the locus of body in Higher Education through the analysis of graduation students' and teachers' speech, who experimented virtualized classes in the pandemic period of Covid-19 in 2020. The context of the study was an institution of Higher Education in Rio Grande do Sul, Brazil. The data was collected from 245 students and 40 teachers by means of a questionnaire made in Google Forms. We found that different understandings in relation to the locus of the body in graduation classes. Such understandings transit between the possibility of renouncing physical and live contact, as in the case of the teaching of theoretical knowledge, and the ones who complain about physical absence mainly in relation to the knowledge acquired in practical classes in the labs and in the interactions with other students and teachers. We conclude that there is still a locus for the body in Higher Education and we learn in the relation with the others and by means of the body senses. Denying the body is to put oneself in the wrong way of human existence because we are the body and we state our presence in the world because of it.

Keywords: Teaching; body; higher education; digital technologies.

RECEBIDO EM: 4/8/2021

ACEITO EM: 4/11/2021

\footnotetext{
1 Autor correspondente. Universidade do Vale do Taquari - Univates, Av. Avelino Talini, 171 - Universitário. Lajeado - RS/Brasil. CEP 95914014. http://lattes.cnpq.br/5204461564869394. http://orcid.org/0000-0002-1875-7226. derllijul@univates.br

2 Universidade do Vale do Taquari - Univates. Lajeado - RS/Brasil. http://lattes.cnpq.br/2668859523186072. https://orcid.org/0000-00019275-9193.

3 Universidade do Vale do Taquari - Univates. Lajeado - RS/Brasil. http://lattes.cnpq.br/8339951598542692. https://orcid.org/0000-00016443-2054.
} 


\section{INTRODUÇÃO}

O ano de 2020 foi diferente em todo o mundo e marcará os subsequentes. A pandemia provocada pelo coronavírus afetou todos os setores da sociedade, da economia à educação, das relações sociais à forma de comprarmos alimentos, provocando-nos a refletir sobre nosso estilo de vida. Apesar dos avanços científicos, da ampliação da produção e do compartilhamento de informações, acentuados pela Internet, voltamos a sentir que ainda há situações em que o domínio da natureza, desejo da ciência moderna, escapa das nossas mãos. O coronavírus fez a humanidade recolher-se, não só em seus domicílios, mas também na tomada de consciência da fragilidade da espécie humana. Por outro lado, nesse momento de crise, também emergiram atitudes de cooperação e de solidariedade, como na busca pela vacina ou na ajuda a pessoas em situação de vulnerabilidade social.

Santos (2020) destaca que a crise, na sua etimologia, tem sentido passageiro, constituindo-se, não raro, numa oportunidade a ser superada para dar origem a um meIhor estado das coisas. Por outro lado, pode tornar-se um período difícil, com cortes nas políticas sociais e a degradação de salários. No caso da pandemia de Covid-19, conforme o autor, ela apenas agravou uma situação de crise a que a população mundial tem sido sujeitada nas últimas décadas, reforçando a injustiça, a discriminação, a exclusão social e o sofrimento.

Historicamente, o ser humano tem sido definido pela sua capacidade de pensar, de raciocinar. A pandemia mostrou o quanto necessitamos da relação física com o outro, da troca de afetos, limitados pela necessidade de distanciamento social, como medida de proteção à saúde. Com certeza, nos damos conta de que somos muito mais que razão, somos carne também, como nos lembra Le Breton (2013).

Não sendo possível a presença física em muitas das atividades que até então fazíamos, houve a necessidade de encontrar outros caminhos, de inventar outras formas de nos relacionarmos, de trabalhar, de ensinar... Como afirma Santin (1993, p. 60), "o homem é um ser vivo dotado de liberdade; por isso, ele se inventa e cria a si mesmo, não como um indivíduo isolado, mas num contexto social".

Nesse âmbito, a cibercultura se fortaleceu (LÉVY, 2010). No cenário pandêmico, mesmo os mais resistentes às tecnologias digitais foram obrigados a se apropriar delas, sobretudo diante da impossibilidade de realizar encontros físicos e presenciais. $\mathrm{O}$ uso das tecnologias digitais, em especial da Internet, foi a alternativa para o comércio, o trabalho home office, atendimentos/consultas médicas e para a educação formal.

No que toca à educação formal no Ensino Superior, contexto que nos interessa discutir neste artigo, o ensino virtual mediado pelas Tecnologias Digitais de Informação e Comunicação (TDICs) já ocorria antes da pandemia. A Educação a Distância (EaD), que não é novidade, difere das aulas presenciais, que se caracterizam pela presença física de alunos e professores, no mesmo espaço e tempo. No ensino presencial fazemo-nos presentes corporalmente. Pensar sobre o lugar do corpo nas aulas de Graduação do Ensino Superior no momento em que a possibilidade de virtualização das aulas se expande é a reflexão a que nos propomos neste artigo. 
A carência de estudos que tratam do corpo no Ensino Superior é constatada na pesquisa bibliográfica realizada por Munhoz e Aquino (2020), que investigaram o uso da ideia de corpo na pesquisa educacional, nos 55 periódicos da área educacional mais bem avaliados (Qualis A1, A2 e B1) pela Coordenação de Aperfeiçoamento de Pessoal de Nível Superior (Capes), publicados no período entre 1997 e 2018. De um total de 73 artigos, a presença do tema corpo relacionado à Educação Superior somente foi encontrada em 6 deles.

Nesse sentido, refletindo sobre o processo de virtualização das aulas que aconteceu em razão da pandemia, questiona-se: Será que estudantes e professores da Graduação do ensino presencial reafirmam a sua existência a partir do corpo, ou se fortalece o desabono dele diante das possiblidades educativas proporcionadas pelo ensino virtual?

A partir dessa inquietação, este artigo teve como objetivo analisar o lugar do corpo no Ensino Superior, a partir de manifestações de estudantes e professores de Graduação, que, em 2020, experimentaram aulas virtualizadas no período da pandemia.

Este estudo justifica-se em razão das contribuições que traz para o Ensino Superior, perante o avanço da virtualização das aulas, podendo auxiliar professores universitários e Instituições de Ensino Superior a conhecerem potencialidades e limitações nessa forma de ensinar. Entende-se também que este artigo dá voz aos dois principais envolvidos nos processos de ensino e de aprendizagem, professores e estudantes, que merecem ser ouvidos diante de um contexto educacional de mudanças e de incorporação de novas metodologias de ensino, mediadas pelas tecnologias digitais.

\section{CORPO E DUALISMOS}

Muitos autores já se debruçaram sobre a história do corpo na trajetória da humanidade (CORBIN; COURTINE; VIGARELLO, 2008a; CORBIN; COURTINE; VIGARELLO, 2008b; COURTINE; VIGARELLO, 2008), apresentando e discutindo o seu lugar nos diferentes períodos históricos e em diferentes sociedades. Pelo fato de que esse tema é denso, é necessário, neste estudo, adentrar em aspectos que nos auxiliem a compreender a conjuntura atual do corpo com o ensino, destacando dualismos que perpassam pelo corpo, tais como: alma/corpo, alma/carne, razão/corpo, sensível/inteligível e presencial/virtual.

Iniciando esse percurso, Santin (1993) comenta que o homem primitivo não tinha consciência do seu corpo, pois ele vivia no seu corpo, confundia-se com ele; por isso, não tinha ideia abstrata de si. Logo, os dualismos são construções da humanidade que não estavam presentes na Pré-História. Nesse período, segundo esclarece Marinho (1980), as aprendizagens, necessárias para a sobrevivência, aconteciam nas atividades do dia a dia, na relação com o outro, seja seu semelhante ou impostas pelo meio natural. Correr, saltar, atacar, defender, levantar, transportar, são práticas diárias, desenvolvidas de maneira "inconsciente", se comparadas às práticas corporais atuais. Numa sociedade sustentada no mito, os rituais e a dança também colocam o corpo num lugar central. 
É na Antiguidade, de acordo com Santin (1993), com o desenvolvimento da filosofia grega, que ocorre a primeira cisão do corpo vivido. O homem, para se conhecer, precisa tornar-se exterior a si mesmo. O conhecimento racional é construído a partir da abstração, que passa do particular para o geral, ou seja, o corpo não diz mais respeito a esse indivíduo, não é o corpo vivido, existencial, mas o corpo abstrato, conceitual, que engloba todos os sujeitos pertencentes àquele conjunto de entes. Assmann (1995, p. 81) alerta que essa generalização é um perigo, "pois não existe 'o corpo geral' de todos, mas sempre 'o corpo concreto' de cada um".

Ainda conforme Santin (1993, p. 47), a partir desse período o homem "sustenta-se sobre o abismo aberto entre dois mundos, aparentemente inconciliáveis e irredutíveis, o mundo do espírito e o mundo da matéria". É em Sócrates e em Platão, conforme Veiga-Neto (2015), que o mito alegórico dos dois mundos, claramente expresso na Alegoria da Caverna de Platão, consolida-se na formulação filosófica de uma realidade dicotômica. Trata-se de uma realidade dividida em duas partes contraditórias: uma, do inteligível e a outra, do sensível; ou, uma, epistêmica e a outra, doxológica.

$\mathrm{Na}$ Idade Média, a valorização da alma, agora no sentido de espiritualidade, sobrepõe-se ao valor do corpo físico. "Os cristãos exigiam um corpo disciplinado e mortificado pela penitência para garantir as virtudes e preservar a pureza espiritual da alma. Assim, o corpo é um símbolo de decadência e uma fonte de vícios e males" (SANTIN, 1993, p. 51). A doutrina dos dois mundos de Platão ajustou-se muito bem à tradição e ao dualismo cristão medieval, na medida em que pregava que "a vida aqui vivida, imperfeita e pecaminosa, se constituiria numa preparação para uma outra vida eterna e divina, a ser vivida num outro mundo e que, em princípio, seria perfeita" (VEIGA-NETO, 2015, p. 123).

Por outro lado, Gélis (2008) nos provoca a olhar para esse momento histórico, para além do corpo como lugar do pecado e carregado de estigmas negativos. "O corpo de Cristo está no centro da mensagem cristã, e o cristianismo é a única religião na qual Deus se inscreveu na história tomando forma humana: a religião do Deus encarnado" (GÉLIS, 2008, p. 23). O autor nos lembra que a fé e a devoção ao corpo de Cristo, muitas vezes mencionado como "carne", fazem do corpo um sujeito da História: "Corpo de Cristo que comemos, que se revela a partir do real e da carne. [...] Corpo magnificado do Filho encarnado, do encontro do Verbo com a Carne. Corpo Glorioso do Cristo da Ressurreição" (GÉLIS, 2008, p. 19).

O dualismo corpo-alma, porém, consolidou-se. Ele se mantém na Idade Moderna, apesar da ruptura do paradigma teocêntrico e do avanço da ciência. Agora ele adquire uma nova roupagem. "O cogito cartesiano superou o dualismo teológico, mas não eliminou a dualidade, porque o substituiu pelo dualismo antropológico" (SANTIN, 1993, p. 17-18). O homem torna-se razão e corpo ou pensamento e existência. Para o projeto do conhecimento científico moderno, o corpo pouco ou nada significa, pois o homem inicia como ser pensante. "Em nenhum momento se escuta o corpo vivo e falante. Ele fica silencioso, submetido aos modelos teóricos [...]" (SANTIN, 1993, p. 53).

A ciência, na concepção positivista, tem como um dos principais princípios a neutralidade entre pesquisador e objeto de pesquisa, ou seja, o sensível e nossas percepções individuais não podem "atrapalhar" a busca pela verdade. O próprio corpo tor- 
nou-se objeto e deseja-se que se torne preciso como uma máquina, razão pela qual a analogia, como trata Le Breton (2013), sempre é do corpo com a máquina e nunca desta com o corpo. Essa objetificação do corpo, de acordo com Gonçalves (2001), contribui para o processo de "descorporalização", ou seja, ao longo da evolução da civilização, o homem foi se tornando o mais independente possível da comunicação empática do seu corpo com o mundo; por isso, reduziu sua capacidade de percepção sensorial e aprendeu a controlar a manifestação de seus sentimentos.

A necessidade do controle das emoções e de disciplinamento corporal na Idade Moderna é muito bem sustentada por Elias (1992), na teoria do processo civilizador. No período da Revolução Industrial, iniciado na Inglaterra, os trabalhadores necessitavam de uma nova conduta diante das novas demandas e organização do trabalho, agora com horários e metas predefinidas a cumprir. Dessa forma, houve necessidade de educar as pessoas corporalmente, restringindo a liberdade de suas ações. Essa educação corporal ocorreu nas instituições de ensino e por meio das práticas esportivas.

Outro movimento voltado ao corpo, aliado à ciência positivista e determinante na disciplina corporal, foi a ginástica moderna, estruturada e difundida a partir de países como a França, Alemanha, Suécia e Dinamarca. Conforme Soares (1998), a ginástica científica afirma-se como parte significativa dos novos códigos de civilidade, que exibem um corpo reformulado, no qual nada pode estar fora do prumo. "Forma-se no século $\mathrm{XIX}$, de um modo mais preciso que em outros momentos da história do homem ocidental, uma pedagogia do gesto e da vontade, configurando-se assim, uma 'educação do corpo'" (SOARES, 1998, p. 17).

Nessa perspectiva, o corpo é visto como o caminho para disciplinar as intenções, os pensamentos, mantendo-se a dualidade corpo-mente. Coube a Merleau-Ponty (1999) tratar da compreensão de que o homem é corpo, de que devemos falar "eu sou corpo" em vez de "eu tenho corpo". Esta compreensão, o corpo fenomenal, contrapõe-se ao pensamento científico clássico, que o vê como objeto. Para o autor, o corpo é o modo próprio de ser-no-mundo. A união entre a alma e o corpo não ocorre por um decreto arbitrário entre objeto e sujeito, mas se concretiza a cada instante, no movimento da existência, argumenta o autor.

Quer se trate do corpo do outro ou do meu próprio corpo, não há outro meio de conhecer o corpo humano senão vivê-lo, quer dizer, cada um é o corpo na medida em que tem um saber adquirido. A experiência do corpo próprio opõe-se ao movimento reflexivo, que nos dá apenas o pensamento do corpo ou o corpo em ideia, e não em experiência do corpo ou o corpo em realidade, conforme expõe Merleau-Ponty (1999).

Assim, podemos questionar como o ensino formal tem compreendido o corpo. Para Gonçalves (2001), a aprendizagem dos conteúdos tem ocorrido sem o corpo, não pelo fato de o estudante ficar sem movimentar-se, mas, sim, pelo fato de os conteúdos e métodos de ensino colocarem o discente num lugar em que ele não vive e pensa com o corpo.

A sociedade atual experimenta novas formas de lidar com o corpo, a partir do avanço das tecnologias digitais, em especial, da difusão da Internet, desde a década de 90 do século passado. Na era da imagem, conforme assevera Assmann (1995), experimentamos uma saturação de signos sobre acontecimentos corporais de toda índo- 
le. Corpos excitados, corpos saciados, corpos famintos, corpos esmagados. Os corpos imagéticos contracenam na excitação, no orgasmo, na fome, na briga, na violência, na guerra. Uma vez que tudo transcorre no mesmo plano da imagem, a diferença das referências se diluem num mesmo âmbito imagético.

Eis o perigo: esvanecida a substância concreta das referências, aplainadas as diferenças dos acontecimentos concretos, a indiferença da mesmice imagética tende a gerar em nós a indiferença emocional. Tudo vira abstrato e geral. Ainda mais se somarmos, a esta ambígua relação com a imagem, o intenso bombardeio de imagens, a que estamos expostos hoje (ASSMANN, 1995, p. 74).

A indiferença em relação ao corpo também se evidencia no discurso científico contemporâneo, ao ser pensado como simples suporte da pessoa. Nesse sentido, Le Breton (2013, p. 5) esclarece: "Ontologicamente distinto do sujeito, torna-se objeto à disposição sobre o qual agir a fim de melhorá-lo, uma matéria-prima na qual se dilui a identidade pessoal, e não mais uma raiz de identidade do homem".

Adentrando na relação corpo e ensino, destacamos duas compreensões que merecem nossa atenção. Uma reconhece e defende que as aprendizagens são internalizadas no corpo. Nas palavras de Serres (2004, p. 75):

Não é preciso que os gestos se repitam muitas vezes para que o corpo se aproprie deles e se torne bailarino ou sapateiro. Encadeamentos de posturas complicadas incorporam-se tão facilmente em seus músculos, ossos e articulações que simplesmente desaparecem esquecidos na memória dessa complexidade. Sem saber como, ele reproduz posteriormente essas sequências de posições mais rapidamente do que as assimila; o corpo imita, armazena e lembra.

A outra, em direção oposta, afasta a existência humana do corpo e questiona sua necessidade na sociedade atual. Le Breton (2013) afirma que o desabono do corpo é um fato vivido por milhões de ocidentais que perderam sua relação de evidência com um corpo que só usam parcialmente. O sonho de uma humanidade livre do corpo tem lógica numa sociedade excessivamente tecnicizada, "no qual o corpo não é mais o centro irradiante da existência, mas um elemento negligenciável da presença" (LE BRETON, 2013, p. 21).

Para Le Breton (2013), a maior recusa que vivemos atualmente não é a dicotomia alma/corpo, mas a oposição vivida pelo homem em relação ao seu corpo. A reconstrução e até mesmo o seu desaparecimento é o empreendimento sobre o qual os engenheiros do biológico se debruçam. Busca-se a superação da precariedade da carne, sua imperfeição na apreensão sensorial do mundo. O esquecimento do corpo na vida cotidiana, no entanto, ignora que a relação do homem com o mundo é física e sensorial.

Qualquer atividade, porém, inclusive o pensar mais abstrato, é atividade corporizada. Mesmo quando desistimos de algo, quando decidimos não agir, nossa corporeidade age para consegui-lo; ela não é fonte complementar de critérios educacionais, mas seu foco principal (ASSMANN, 1995). Corroborando a ideia da relevância do corpo, Serres (2004, p. 18) lamenta não ter aprendido mais cedo sua força criadora e frisa que "o que nos distingue das máquinas é unicamente nossa carne divina; a inteligência humana se distingue da artificial apenas pelo corpo". 
Por fim, no contexto atual, cabe apontar mais um dualismo, presencial/virtual, relacionado à forma de ensinar, ao ensino presencial e à EaD. Quanto à compreensão de EaD, Joye, Moreira e Rocha (2020) apresentam uma grande variedade de terminologias relacionadas a ela, desde os estudos por correspondência até a proposta Blended-Learning (ensino híbrido). Entendem, no entanto, que a EaD é caracterizada pelo fato de professores e alunos mediarem seu conhecimento por meio de interação síncrona e/ ou assíncrona, em espaços e tempos distintos, com ou sem uso de artefatos digitais. "O termo 'a distância' explicita sua principal característica: a separação física do professor e do aluno em termos espaciais, não excluindo, contudo, o contato direto dos alunos entre si ou do aluno com o professor, a partir do uso dos meios tecnológicos" (JOYE, MOREIRA; ROCHA, 2020, p. 7).

Nesse momento de pandemia, a EaD, em especial a virtualização das aulas realizada de forma síncrona, permitiu desenvolver uma relação pedagógica, em espaços diferentes, mas mantendo todos juntos no mesmo tempo. O ensino virtualizado síncrono, assim como a EaD, também dispensa o lugar físico no qual todos estão presentes para a aula, todavia ele diferencia-se pela necessidade de sincronicidade. Lévy (1996) contribui para entendermos como esse novo lugar se reconstrói. Ele menciona que a sincronização substitui a unidade de lugar e a interconexão, a unidade de tempo, num movimento de desterritorialização.

Em virtude das restrições do ensino presencial, o ensino virtual, conforme Santinello, Costa e Santos (2020), está sendo adotado em Instituições de Ensino Superior (IES), em especial, em IES privadas, que, mediante seu aparato estrutural e financeiro, desenvolvem as aulas utilizando essa metodologia de ensino, que é permitida legalmente pelas legislações educacionais brasileiras. Ela se apresenta tanto pelo seu caráter inovador quanto para uma possível abertura para aumentar a mercadorização da Educação Superior.

Nessa perspectiva, os aportes teóricos nos instigaram a investigar junto a professores e estudantes da Graduação, o que eles têm a nos dizer sobre a experiência vivida em tempos de aulas virtualizadas. Mantemos viva a questão: Será que ainda há lugar para o corpo no Ensino Superior atual?

\section{PROCEDIMENTOS METODOLÓGICOS}

A pesquisa caracteriza-se como qualitativa (BODGAN; BIKLEN, 1994). Quanto aos fins, é descritiva. A investigação ocorreu em 2020, no período de pandemia de Covid-19, em uma Instituição de Ensino Superior. Esta IES deu continuidade às suas aulas presenciais de forma virtual e síncrona, utilizando Ambientes Virtuais de Aprendizagens (AVAs) e TDICs. Os processos de condução do ensino, seleção e produção de conteúdos foram elaborados pelos próprios professores do ensino presencial. Cabe destacar que eles tiveram momentos formativos ofertados pela instituição empregadora quanto ao uso de AVAs e de recursos tecnológicos para a docência.

Por meio de um questionário com 15 perguntas, abertas ou de múltipla escolha, foram produzidas informações sobre a experiência discente e docente nas aulas virtualizadas. Os estudantes foram questionados a respeito de suas aprendizagens e os profes- 
sores, em relação à docência virtual, destacando aspectos que consideraram positivos, bem como diferenças percebidas em relação à modalidade presencial. O questionário foi elaborado no Google Forms e encaminhado via e-mail aos participantes da pesquisa.

Responderam ao questionário 245 estudantes (4,72\%) de uma população de 5.192 e 40 professores (12,35\%) de um total de 324 da IES. A adesão foi voluntária e por acessibilidade, atendendo aos critérios qualitativos estabelecidos: estudantes e professores de todas as áreas de conhecimentos da instituição; cursos nos quais as aprendizagens procedimentais predominam e cursos nos quais aulas práticas são consideradas fundamentais para aprendizagens procedimentais da profissão. Quanto aos estudantes, foram excluídos os do primeiro semestre, pelo fato de terem tido apenas um mês de aulas presenciais em 2020. Os estudantes e professores eram oriundos das seguintes áreas de conhecimento: saúde, humanidades, ciências sociais, gestão, educação, ciências exatas, engenharias e tecnológicas.

A coleta de informações ocorreu nos meses de maio e junho de 2020, o que corresponde ao final do primeiro semestre letivo, período no qual as aulas estavam acontecendo de forma virtualizada. Naquela ocasião, estudantes e professores já haviam experimentado dois meses de ensino virtualizado.

Em relação à análise das informações obtidas nos questionários, optou-se pela análise de discurso das questões abertas, visando a compreender e interpretar as respostas dos professores e estudantes quanto à relação do corpo com o ensino e a aprendizagem. Conforme Orlandi (2020, p. 8), na análise de discurso não temos como não interpretar; ela "nos coloca em estado de reflexão e, sem cairmos na ilusão de sermos conscientes de tudo, permite-nos ao menos sermos capazes de uma relação menos ingênua com a linguagem". Para isso, a autora menciona a necessidade de mediação teórica permanente, em todos os passos da análise, pois "o discurso é o lugar onde se pode observar essa relação entre língua e ideologia, compreendendo-se como a língua produz sentidos por/para os sujeitos" (ORLANDI, 2020, p. 15).

Nesse momento, portanto, no qual experimentamos profundas transformações na forma de ensinar, mediadas pelas TDICs, opta-se por dialogar com autores que compreendem que o homem faz parte de um mundo vivido (LE BRETON, 2009; LE BRETON, 2013; LE BRETON, 2016; MERLEAU-PONTY, 1999; SANTIN, 1993; SANTIN, 1995; SERRES, 2001; SERRES, 2004). Esses autores possibilitam compreender e analisar os discursos de estudantes e professores sobre o lugar que o corpo ocupa no processo de virtualização das aulas. Além disso, buscamos referenciais produzidos em 2020 (SANTOS, 2020; NEUENFELDT et al., 2020; FERREIRA et al., 2020, SANTINELLO; COSTA; SANTOS, 2020), que tratam da singularidade do momento que vivemos por causa da pandemia de Covid-19.

Quanto aos cuidados éticos, todos os participantes autorizaram o uso das informações na pesquisa por meio do Termo de Consentimento Livre e Esclarecido, estando cientes dos objetivos da pesquisa, dos riscos e benefícios, bem como da garantia do sigilo do nome na divulgação da pesquisa. Dessa forma, ao fazer uso das respostas, utilizamos os códigos professor 1 , professor 2 ... e estudante 1 , estudante 2 ... A instituição investigada também concedeu autorização para realizar o estudo. 


\section{AS AULAS PRECISAM CONTINUAR...}

A análise do discurso dos estudantes e professores quanto à experimentação do ensino virtual síncrono nos possibilitou constatar compreensões diferentes em relação ao lugar do corpo nos processos de ensino e aprendizagem. Elas transitam entre a possibilidade de um ensino que renuncia ao encontro presencial com os corpos físicos e aquelas que reclamam da ausência do corpo do professor e dos colegas de aula, bem como dos espaços de socialização que a Universidade disponibiliza e possibilita.

Considerando o contexto pandêmico do período da pesquisa, no qual muitas atividades presenciais foram paralisadas ou comprometidas quanto à possibilidade de ocorrerem integralmente, o ensino virtual foi o caminho possível para a continuidade das aulas da Graduação, conforme foi evidenciado nas falas dos estudantes:

Mesmo no caos que estamos vivendo, nós continuamos com a nossa aprendizagem e em busca dos nossos sonhos, não parando no tempo (estudante 1).

Deu para seguir as aulas normalmente, sem perder os conteúdos (estudante 2).

Percebemos nas falas a preocupação dos estudantes com a não paralisação dos estudos, com as aprendizagens necessárias para a formação profissional, indispensáveis para avançar no curso de Graduação e não alterar planos pessoais, tais como a formatura, a manutenção do emprego ou a conquista de um lugar melhor no mercado de trabalho. $O$ ensino virtual possibilitou o prosseguimento dos estudos, abdicando-se, nesse momento, a presença corporal na Universidade.

A ideia de continuidade diante de um contexto de incertezas também é manifestada por professores. Há, no entanto, preocupação com o novo momento vivido no Ensino Superior, no qual novas formas de ensinar tiveram de ser construídas e aprendidas, tal como evidenciamos na fala a seguir:

A virtualização permite, por um lado, manter as pessoas no foco e ocupadas de forma saudável. Por outro lado, gera um estresse por exigir demais e não permitir que se possa viver o cuidado com o ser humano que o momento atual exige (professor 1).

Entre os aspectos em que a pandemia nos desacomodou e permitiu rever nossos hábitos, Santos (2020) menciona o fato de poder ficar em casa e voltar a ter tempo para ler um livro, conviver mais com os filhos, consumir menos, dispensar o vício de passar o tempo nos centros comerciais. Percebeu-se, assim, a existência de outras possibilidades de realização pessoal. Essa, contudo, não é a realidade da maioria da população, pois muitos trabalhadores perderam seu emprego ou sentem-se inseguros quanto à continuidade de serem mantidos nos postos de trabalho.

No caso dos professores, estudos como o de Oliveira e Santos (2021) alertam para o adoecimento mental, acentuado pelas mudanças ocasionadas no trabalho com a migração do ensino presencial para o remoto, que exige um novo perfil profissional e novas performances para o atendimento das demandas com qualidade. Souza et al. (2021), ao investigarem a docência de professores do Ensino Fundamental, também identificaram que a situação pandêmica repercutiu na necessidade de os professores 
trabalharem em casa concomitantemente com as obrigações domiciliares, gerando intenso trabalho, estresse, ansiedade, medos, preocupações, insegurança, saudades da escola e dos estudantes.

As novas demandas para a docência no Ensino Superior no período de pandemia também são destacadas em estudo realizado por Neuenfeldt et al. (2020). Entre as principais dificuldades está a gestão do tempo, pois aumentou a demanda de o professor estar disponível aos estudantes em diferentes momentos além do tempo da aula em si, a necessidade de elaboração de novos materiais didático-pedagógicos e de se capacitar para o uso de novas tecnologias digitais. Mesmo, porém, diante de um contexto de pandemia, concordamos com Guimarães (2019, p. 221) ao afirmar que "o professor não deve curvar-se à ideologia que, em muitas ocasiões, infecciona a sua profissão, em um contexto perverso, mas necessita considerar a circularidade política, ética e estética que dá retorno à sua prática cotidiana".

Conforme evidencia a fala do professor 1 , as novas demandas conduziram os professores novamente ao estilo de vida "atarefado", relegando a um segundo plano o cuidado de si. As exigências do ensino virtual, tais como as novas aprendizagens relacionadas ao domínio das tecnologias digitais necessárias para o acompanhamento das aulas e as inúmeras tarefas solicitadas aos estudantes, que exigem tempo para o preparo e a correção, é a preocupação do professor. Continua-se ignorando que o corpo tem limites e não se escutam os sinais de cansaço que o corpo emite, tais como a ansiedade e a depressão.

O ensino virtualizado exigiu novas competências do professor, sem dispor de um tempo adequado para desenvolvê-las, pois as aulas precisam continuar, gerando sobrecarga de trabalho. Soma-se a esse contexto o fato de estudantes e professores passarem a ficar mais e mais tempo diante da tela do computador ou do smartphone, conforme evidenciado no discurso do estudante 3 :

Houve um aumento da exposição à tela do computador, gerando um esgotamento físico e em parte emocional [...] muitos estímulos à volta (estudante 3).

Podemos destacar que, momentaneamente, houve a tomada de consciência de que somos corpo, um corpo que é de carne e osso, que tem sentimentos, que sente alegrias e tristezas, que sente frio, fome, dor, que é finito; no entanto, diante das novas demandas, novamente emerge o esquecimento de que somos corpo. O homem, diz Le Breton (2009), é diferente da máquina; contudo, quanto mais o corpo perde o valor moral, mais cresce o valor técnico e mercadológico, aproximando-se da compreensão de um corpo-objeto.

\section{A EFÊMERA TOMADA DE CONSCIÊNCIA DE QUE SOMOS CORPO}

Além da possibilidade de continuidade das aulas, houve mais um aspecto destacado como positivo pelos estudantes no ensino virtual síncrono: a economia de tempo e dinheiro. $O$ estudante 4 comenta:

O fato de não necessitar me deslocar até a Universidade economiza tempo e o valor do transporte, além de ter o diferencial do conforto do lar (estudante 4). 
Em estudo realizado em Portugal, com os estudantes da Escola Superior de Saúde Norte da Cruz Vermelha Portuguesa, Ferreira et al. (2020) constataram que entre as medidas adotadas no plano de contingência que mais contribuíram para reduzir o impacto da Covid-19 está a rápida adaptação à criação de ambientes favoráveis ao Ensino a Distância síncrono, com o uso de plataformas educativas. Também detectaram que a efetivação do ensino a distância síncrono permitiu aos estudantes economia financeira e de tempo.

Por outro lado, na fala do estudante anteriormente mencionado, além da questão econômica, convém destacar que está oculto um corpo, que, para ter aulas presenciais, desloca-se por horas até a Universidade, muitas vezes após um longo dia de trabalho. É um corpo que, diante do sonho da formação superior, tornou-se resiliente ao deslocamento, à dupla jornada de trabalho e de estudo. Esse estudante, que tira do seu trabaIho o sustento e o financiamento de seu estudo, percebe que o ensino virtual the possibilita uma rotina diária na qual é possível refletir, no sentido de se voltar para si, para seu corpo. $O$ estudante, mesmo que momentaneamente, percebe-se como corpo fenomenal (MERLEAU-PONTY, 1999), que consegue olhar para a sua relação com o mundo vivido e não mais como um corpo-objeto (LE BRETON, 2009), destituído de sentimentos e de desejos. Engolido pela rotina diária, porém, como destaca Le Breton (2013), esquecemos do corpo na vida cotidiana e ignoramos que a relação do homem com o mundo é física e sensorial e assim deixamos de escutar nosso corpo.

A rotina diária dos estudantes nos faz pensar sobre essa condição de estudante-trabalhador. Santos (2020) explica que, nos últimos 40 anos, o neoliberalismo crescente e dominado pelo capital financeiro global sujeitou todas as áreas sociais ao modelo de negócio do capital, entre elas a educação, a saúde e a segurança social. Destaca-se o forte investimento do setor privado e a retirada do setor público, que passou a ser depreciado e caracterizado como ineficiente e corrupto. O Ensino Superior no Brasil também segue essa lógica e, nesse sentido, as universidades públicas não absorvem todos os estudantes que sonham com a formação superior. Resta recorrer às instituições privadas, que se apresentam como possibilidade diante das lacunas deixadas pelo Estado. Cada vez mais, contudo, torna-se mais difícil o estudante dedicar-se somente aos estudos, dificuldade que se acentua nas instituições privadas.

\section{O CORPO AINDA TEM LUGAR NO ENSINO SUPERIOR}

Em razão da pandemia, emerge uma nova experiência de ensino, de modo que não há mais a necessidade de se deslocar fisicamente todos os dias para a universidade. Um olhar mais atento para as especificidades dos cursos e das possibilidades de ensino mediadas pelas TDICs leva-nos a perceber que estudantes e professores destacam que o ensino virtualizado atende ás necessidades das disciplinas nas quais os conhecimentos teóricos (conceituais) predominam:

As aulas teóricas a gente consegue aprender bem, como se estivesse na aula presencial (estudante 5).

Tendo em vista serem conteúdos conceituais foi possível "virtualizar" todos (professor 2). 
Essas falas, ao remeterem às "aulas teóricas" e aos "conteúdos conceituais", induzem a nos debruçarmos sobre a etimologia da palavra teoria. Para tal, recorremos a Veiga-Neto (2015, p. 121), ao argumentar que teoria "vem da forma grega theōria, cujo sentido é observar, examinar ou escrutinar, [...]" uma forma de enxergar melhor aquilo que se conhece, não se tratando de um ver propriamente físico, com os olhos, mas de um ver com a razão.

Conforme exposto, "não se trata de um ver propriamente físico", de modo que não necessitamos dos sentidos corporais para teorizar. Logo, há um reforço da cisão corpo e mente (SANTIN, 1993). Assim, para estudantes e professores, a teoria, a especulação pela razão, o exercício do pensamento são possíveis de serem desenvolvidos virtualmente, sem a presença física do corpo, sem prejuízos para a aprendizagem. Como, no entanto, pensar sem o corpo físico presente? Como se dá o pensamento numa realidade virtualizada propriamente dita?

Por outro lado, constata-se que nas disciplinas em que há aprendizagens procedimentais, que no discurso dos estudantes é expresso nas palavras "ir a campo" ou "aulas práticas", eles sentem a falta do corpo se fazer presente, da convivência em espaços como a sala de aula e os laboratórios. Para essas aprendizagens, relacionadas ao saber-fazer, contextualizadas com a profissão, a experimentação corporal possibilita apreender o mundo que nos chega pelos sentidos corporais e é apontada como imprescindível, como ilustram as falas na sequência:

Sinto que minha aprendizagem é mais efetiva quando presencial. Algumas aulas seriam melhor ir a campo para entender o conteúdo com a pandemia (estudante 6).

Nas práticas o aprendizado é maior em grupo, no laboratório e nos locais de atuação, vendo e fazendo a gente aprende mais (estudante 7).

Não é a mesma coisa. Por exemplo, disciplina de Educação Corporal, onde envolve a parte apalpatória para encontrar pontos anatômicos, no qual não está sendo possível realizar apenas na teoria (estudante 8).

Recorremos novamente a Veiga-Neto (2015, p. 120), agora para compreendermos o significado do termo "prática". Conforme o autor, em todas as formas de escrita, seja de origem latina practice, do radical indo-europeu prāk, que derivam o verbo grego prassein, o substantivo práxis ou praktos> praktikos, ou da língua portuguesa do século 15 , relacionado às palavras practica, platica e pratica, não está implícita qualquer dependência entre a ação e aquilo que se possa pensar e dizer sobre elas. Por prática entendia-se um conjunto de ações, em geral aprendidas, repetitivas, quase automáticas e habituais. Algo que não fosse habitual não era entendido como prática. O termo prática como hábito contrastava com a teoria, o que nos leva a entender a separação que ainda hoje persiste. Segundo esse entendimento, presente na fala dos estudantes, a prática é independente da teoria, observando-se que a primeira necessita de presencialidade corporal e a segunda é possível de ser virtualizada.

Por outro lado Oliveira (2017), que discute possibilidades didático-pedagógicas para motivar os estudantes no Ensino Superior, destaca que as aulas práticas aproximam o conteúdo da vivência do aluno, bem como permitem que ele visualize o que está sendo estudado, possibilitando-lhe deparar-se com resultados imprevistos e desafiá-lo 
a questioná-los. Para que as aulas práticas contribuam com as aprendizagens dos estudantes, porém, é necessário que se relacionem com os conteúdos que estão sendo trabalhados.

Ainda, no que diz respeito às aulas práticas, que compreendemos como as experiências pedagógicas que tocam os estudantes pelo corpo por meio dos sentidos corporais, quando o estudante 8 diz que sente falta da parte "apalpatória", emergem duas questões para discutirmos: o fato de que a virtualização não consegue substituir a experiência prática em si e a outra, que há aprendizagens que acontecem pelo contato físico.

Quanto à questão das aprendizagens por meio da experiência prática em si, não se ignora que outras formas de ensinar sejam possíveis, tais como vídeos educativos e simuladores virtuais. Estas formas de ensino, contudo, são alternativas, são outras formas de ensinar. Como alega Merleau-Ponty (1999), a ideia da coisa não substitui a coisa em si. Quer se trate do corpo do outro ou do meu próprio corpo, não há outro meio de conhecer o corpo humano senão vivê-lo, quer dizer, cada um é o corpo na medida em que tem um saber adquirido.

Merleau-Ponty (1999) ainda esclarece que a experiência do corpo próprio se opõe ao movimento reflexivo que nos transmite apenas o pensamento do corpo, ou o corpo em ideia, não em experiência do corpo ou o corpo em realidade. Por essa razão, "sentir" é uma questão importante para o ser humano. Assim sendo, não há como substituir as aprendizagens que ocorrem por meio da experimentação corporal.

Em relação ao contato corporal, há aprendizagens que acontecem no corpo, como destaca Serres (2004). Essas aprendizagens corporais também não podem ser negadas, substituídas e caírem no esquecimento ou, então, passarem o entendimento de que o corpo é imperfeito e, por isso, a apreensão do mundo pelos sentidos não tem valor. Le Breton (2013, p. 203) reforça que "o sensível é em primeiro lugar a tatilidade das coisas, o contato com os outros ou os objetos, o sentimento de estar com o pés no chão".

A presente investigação evidenciou que as aprendizagens também se dão no corpo, pelo tato, e carecem do "contato" físico, que não é possível virtualmente. Apalpar é uma forma de conhecer; por isso,o estudante sente sua falta. Apalpar significa "tocar com a mão para conhecer pelo tato; tatear; tocar brandamente, sondar, examinar-se com as mãos" (FERREIRA, 2000, p. 49).

O termo "apalpar" significa "conhecer, sondar, examinar-se", que nos remete à aprendizagem que se serve do outro para obter informações que auxiliem a compreender o que se estuda. Por isso, o outro, conforme Serres (2004, p. 56), me auxilia a compreender o mundo, "o outro faz com que a minha carne se misture a ela própria: além do animal que habita em mim, em meu corpo entram os outros e, sobretudo, outro; misturado, mestiçado, perpassado, perdido em meio a essa grande multidão [...]".

A subtração do tato é a privação do gozo do mundo, pois ele traduz-se num contato pessoal com o mundo, em que os outros sentidos, em particular a visão, são impotentes (LE BRETON, 2016). O ensino virtual, portanto, tem essa limitação, por não possibilitar a experiência corporal do estudante com o mundo. 
Quanto às aprendizagens que se dão com o outro, estudantes e professores mencionam a relevância da interação que ocorre na presença física, para os processos de ensino e de aprendizagem:

Acredito que aulas presenciais, com a integração de todos os colegas e o professor faço uma melhor compreensão do conteúdo (estudante 9).

Nada se compara ao contato físico e o olho no olho, na relação professor e aluno. Conversas fluem mais na forma presencial (estudante 10).

A falta de interação direta com os alunos, o "olho no olho", a vida que preenche uma sala de aula. A gente capta o ânimo e a motivação (ou não) dos alunos pelos gestos, posturas, olhares, e isso se perde na aula remota (professor 3 ).

A impossibilidade de fazer a leitura dos "rostos/corpos" (professor 4).

O que querem nos dizer estudantes e professores com esse discurso comum sobre a falta do "olho no olho"? Está a se falar de uma leitura corporal que somente é possível perceber na presença física. Não é a imagem facial ou corporal que o estudante ou o professor apresentam como cartão de visita nas redes sociais. Trata-se do corpo vivido que se faz presente na sala de aula, na sua totalidade, que expressa no olhar a motivação, a indiferença, o cansaço, a tristeza e tantos outros sentimentos possíveis. Essa leitura do outro, apontada por professores e estudantes, não é possível, não na sua totalidade, no ensino virtual, seja pela impossibilidade de apreender o outro pelo tato, seja pela má resolução da imagem transmitida daqueles que se apresentam diante da tela do computador ou do smartphone.

Le Breton (2016) nos ajuda a entender o sentido de ver: "Ver procede do latim videre, oriundo do indo-europeu veda, que significa 'sei', de onde derivam termos como evidência (que é visível), providência (prever segundo orientações divinas". O autor menciona que o olho vê as coisas ao pé da letra, pois só vemos as coisas que se mostram, enquanto o tato nos auxilia na leitura do mundo.

Dessa forma, ver-se é uma limitação no ensino virtual; não ver ou o desaparecimento dos estudantes do campo da visão atormenta ainda mais os professores. Não ver os alunos dificulta compreender como eles estão envolvidos com a aula. Nesse sentido, Le Breton (2016, p. 75) ressalta que "ter os olhos pousados sobre alguém é uma maneira de fisgá-lo para não deixá-lo escapar". Fisgar o estudante com o conhecimento, esse é o desafio do professor e, por essa razão, compreende-se a necessidade do "olho no olho".

O estudante, por sua vez, também sente falta do olhar do professor, pois, como menciona Le Breton (2016), a visão também é aprendizagem. “O ver é inesgotável, já que as maneiras de olhar o objeto são infinitas, mesmo se na vida cotidiana uma percepção mais funcional baste para guiar os deslocamentos ou fundamentar as ações" (p. 69).

Merleau-Ponty (1999, p. 105) acrescenta que "olhar um objeto é vir habitá-lo, e dali apreender todas as coisas segundo a face que elas voltam para ele". O corpo, contudo, para o autor, não pode ser comparado a um objeto físico, porém à obra de arte. Uma experiência tátil do braço também o é do antebraço e do ombro, é um nó de sig- 
nificações vivas, da mesma forma que na arte. Num poema, num quadro, numa peça musical, o sentido só é acessível por um contato direto, que irradia sua significação sem abandonar seu lugar temporal e espacial.

Analisando o ensino virtual, portanto, percebemos que ele permite olhar para apenas uma face do corpo, a face que se apresenta na tela do computador ou do smartphone. Trata-se de uma tela na qual o horizonte também não é visível, diferente da sala de aula presencial, que permite a vista de todos os espaços, perspectivas e faces dos corpos. Numa analogia, podemos percebê-lo no exemplo da casa de Merleau-Ponty (1999, p. 105-106): "a casa ela mesma não é a casa vista de lugar algum, mas a casa vista de todos os lugares".

Os professores convergem em torno da compreensão de que não conseguem sentir o estudante na aula virtual. Concomitantemente, convivem com a dúvida em relação à presença corporal dos alunos, no outro lado da conexão. Essa dúvida atormenta o professor que habitualmente ensina na presença do outro, que, a partir da leitura corporal, também orienta sua metodologia de ensino:

Sinto falta dos alunos, de ver a reação deles, muitos não gostam de abrir as câmeras e falar no microfone, acabam somente interagindo pelo chat, e com isso nem sempre percebemos se estão conectados ou não nas aulas (professor 5).

A falta do contato físico em parte não tem como ser "resolvido". Isso deixa a aula carente no aspecto afetivo e abre uma certa ansiedade e angústia (professor 6).

Não temos o "cheiro da sala de aula": uma escuta e um processo de ensino e aprendizagem se faz com os cinco sentidos (professor 7)!

As falas mencionadas trazem à tona alguns sentimentos dos professores, presentes nas lembranças das aulas presenciais, que contrastam com o distanciamento dos estudantes na aula virtual. Nesse sentido, os estudantes, muitas vezes, permanecem ocultos, interagindo pouco, sem desenvolverem um vínculo afetivo com o professor ou com os colegas de aula.

Quando o professor nos diz que "não temos o cheiro da sala de aula" no ensino virtual, o que está oculto nessas palavras? A virtualização permite a transmissão da imagem, do som, mas não podemos sentir o cheiro. Essa expressão do professor nos faz pensar em outra direção: que cheiros são estes que caracterizam uma sala de aula presencial?

A sala de aula é um lugar de trocas entre professor e estudantes, que estão num mesmo tempo e espaço, com um objetivo de aprendizagem. Conhecer o outro, porém, faz parte do processo de ensinar, assim como eu me dispor corporalmente a uma relação que se constrói. Esse "cheiro da sala de aula" não está presente no ensino virtual, da mesma forma que o estudante pode ocultar-se nas videoconferências, além de ser um ensino sem contato físico. Em relação ao professor que sente falta do cheiro da sala de aula, Le Breton (2016) nos leva a compreender que são os valores culturais que "cheiram" e que são mais difíceis de serem identificados no ensino virtual, principalmente quando os estudantes mantêm as câmeras fechadas. 
Um grande desafio que se coloca é refletirmos como o estudante decifra o mundo quando seus sentidos são isolados ou fragmentados. "Não é possível isolar os sentidos para examiná-los um após outro senão através de uma operação de desmantelamento do sabor do mundo. Os sentidos estão sempre presentes na sua totalidade" (LE BRETON, 2016, p. 59). Por outro lado, no ensino virtual, para além da visão e da audição, os demais sentidos corporais ainda não têm lugar.

Serres (2001, p. 314) contribui com a compreensão de que o corpo interage com o mundo na sua totalidade, por meio de todos os sentidos que se fazem presentes concomitantemente: "a mente vê, a linguagem vê, o corpo visita", ou seja, o corpo apreende o mundo na sua complexidade, o corpo cheira uma rosa e mil odores no seu entorno e, ao mesmo tempo, experimenta o mundo pelos demais sentidos, sem conseguir isolar-se, como na linguagem e no pensamento. O corpo não se comporta como receptor passivo; ele ama o movimento, salta, corre, dança, conhece a si mesmo e descobre sua existência, no ardor muscular, nos limites da fadiga (SERRES, 2001).

Em certo sentido, podemos sustentar que, no ensino virtual, estudantes e professores também se fazem presentes corporalmente, pois a existência se dá pelo corpo; é o corpo que se faz presente na tela, na imagem que é transmitida. É o sujeito que fala e se faz presente. A interação social, sem dúvida, também é possível, o que vem ocorrendo nas últimas décadas pelas redes sociais, tais como Facebook, Instagram e aplicativos, como é o caso do WhatsApp. Os estudantes, porém, destacam que o ensino virtual não substitui a interação presencial, como podemos ver a seguir:

A convivência com os demais colegas forma uma rede bem importante tanto em relação à discussão de problemas da disciplina como também no compartilhamento de experiências (estudante 11).

A Universidade, na minha opinião, é muito mais do que um local de mero aprendizado técnico, é um local de troca, de convívio, de debate, de formação de opinião, o que nas aulas virtuais não ocorre (estudante 12).

Percebe-se que os estudantes sentem necessidade de interagir com os colegas, de conhecê-los, assim como reconhecem que a universidade é mais que a sala de aula. É o reconhecimento de que se aprende e se apreende o mundo pela "visita", como destaca Serres (2001), momento em que todos os sentidos corporais estão ativos e atuantes ao mesmo tempo. Já o espaço cibernético, conforme Le Breton $(2013,142)$, apresenta-se como "um mundo em que as fronteiras se misturam e o corpo se apaga, em que o outro existe na interface da comunicação, mas sem corpo, sem rosto, sem outro toque além do olhar da tela".

\section{CONSIDERAÇÕES FINAIS}

Cabe ainda tecermos algumas considerações. Voltemos, então, ao problema da pesquisa: Será que estudantes e professores do ensino presencial da Graduação, após terem vivenciado aulas virtuais, reafirmam a sua existência a partir do corpo ou se fortalece o desabono diante das possiblidades educativas proporcionadas pelo ensino virtual? 
Ao analisar o ensino virtual, emergiu a essência do ensino presencial no Ensino Superior, desvelando sua singularidade e características que Ihe são próprias. Elas permaneceram vivas na memória corporal de estudantes e professores, mesmo num período em que o ensino presencial não foi possível.

Constatou-se que o ensino virtual é compreendido como uma alternativa que supre as necessidades em termos de aprendizagens teóricas, possíveis de ocorrerem a distância, mediadas pelas tecnologias digitais. Nesses processos de ensino e de aprendizagem, estudantes abdicam da presencialidade física, do corpo em si.

Nesse sentido, poderíamos ser induzidos a pensar que o Ensino Superior caminha para a negação do corpo ou que ele se tornou obsoleto, como afirma Le Breton (2013). Estudantes, contudo, reivindicam a presencialidade na universidade e aprendizagens que se dão no corpo, bem como sentem necessidade de interagir com colegas e professores, no mesmo lugar e ao mesmo tempo, pois, para eles, "nada se compara ao contato físico e ao olho no olho".

O ensino virtual tem limitações para as aprendizagens que se dão no corpo, pois os sentidos corporais permanecem restritos à visão e à audição, à imagem e à fala. 0 corpo também aprende e apreende o mundo pelo tato, pelo olfato e pelo paladar, o que ficou evidente quando os estudantes dizem que o ensino virtual não é a mesma coisa que o presencial, que não há como virtualizar aprendizagens que ocorrem, por exemplo, ao se "apalpar".

A falta da relação "olho no olho" também é manifestada pelos professores, assim como sentir o "cheiro da sala de aula", que não é possível no ensino virtual. Não se trata de uma defesa do ensino presencial, mas de reconhecer suas potencialidades, pois, como os professores manifestam, o ensino presencial possibilita estar mais próximo dos estudantes, senti-los a partir da forma como cada um se expressa pelo corpo, o corpo vivido que se faz presente.

Não desconsideramos que há aprendizagens possíveis de serem virtualizadas e a potencialidade das TDICs na mediação do ensino virtual. A pesquisa, contudo, demonstrou que ainda há lugar para o corpo no Ensino Superior e que aprendemos na relação com o outro e por meio dos sentidos corporais. Negar o corpo é colocar-se na contramão da essência da existência humana, pois somos corpo e nos fazemos presentes no mundo a partir dele.

Por fim, o tema não se esgota. Novos estudos investigando o lugar do corpo em outros níveis de ensino, tais como na Educação Infantil e Anos Iniciais do Ensino Fundamental tornam-se relevantes. O que está sendo desenvolvido com esses estudantes no período de ensino não presencial no período de pandemia? Que aprendizagens didático-pedagógicas foram construídas em tempos de pandemia? Essas são algumas questões que merecem ser investigadas.

\section{REFERÊNCIAS}

ASSMANN, Hugo. Paradigmas educacionais e corporeidade. 3. ed. Piracicaba: Unimep, 1995.

BOGDAN, Robert.; BIKLEN, Sari. Investigação qualitativa em educação: uma introdução à teoria e aos métodos. Porto: Porto Editora, 1994. 
CORBIN, Alain; COURTINE, Jean-Jacques; VIGARELLO, Georges. História do corpo: da renascença às luzes. 2. ed. Petrópolis: Vozes, 2008a.

CORBIN, Alain; COURTINE, Jean-Jacques; VIGARELLO, Georges. História do corpo: da revolução à guerra. 2. ed. Petrópolis: Vozes, 2008b.

COURTINE, Jean-Jacques; VIGARELLO, Georges. História do corpo. As mutações do olhar: o século XX. 2. ed. Petrópolis: Vozes, 2008.

ELIAS, Norbert. A busca da excitação. Portugal: Difel, 1992.

FERREIRA, António; PRÍNCIPE, Fernanda; PEREIRA, Henrique; OLIVEIRA, Isabel; MOTA, Liliana. COVimpact: pandemia COVID-19 nos estudantes do Ensino Superior da saúde. Revista de Investigação \& Inovação em Saúde, v. 3, n. 1, p. 7-16, 2020. Disponível em: https://doi.org/10.37914/riis.v3i1.80. Acesso em: 5 mar. 2021.

FERREIRA, Aurélio Buarque de Holanda. Miniaurélio século XXI: o minidicionário da língua portuguesa. 4. ed. RJ: Nova Fronteira, 2000.

GÉLIS, Jacques. O corpo, a igreja e o sagrado. In: CORBIN, Alain; COURTINE, Jean-Jacques; VIGARELLO, Georges (a). História do corpo: da renascença às luzes. 2. ed. Petrópolis: Vozes, 2008. p. 19-130.

GONÇALVES, Maria Augusta Salin. Sentir, pensar e agir: corporeidade e educação. 5. ed. Campinas: Papirus, 2001.

GUIMARÃES, Jairo de Carvalho. A prática competente do professor universitário: por uma emancipação discente. Contexto \& Educação, ljuí, a. 34, n. 107, p. 210-233, jan./abr. 2019. Disponível em: https://www. revistas.unijui.edu.br/index.php/contextoeducacao/article/view/7153. Acesso em: 28 jul. 2021.

JOYE, Cassandra Ribeiro; MOREIRA, Marília Maia; ROCHA, Sinara Socorro Duarte. Educação a Distância ou Atividade Educacional Remota Emergencial: em busca do elo perdido da educação escolar em tempos de COVID-19. Research, Society and Development. Vol. 9, n. 7, p. 1-29, Disponível em: https://doaj.org/ article/9dba5722fd104e229d182c768e455b46. Acesso em: 5 de mar. 2020.

LE BRETON, David. A sociologia do corpo. 3. ed. Petrópolis, RJ: Vozes, 2009.

LE BRETON, David. Adeus ao corpo. 6. ed. Campinas, SP: Papirus, 2013.

LE BRETON, David. Antropologia dos sentidos. Petrópolis, RJ: Vozes, 2016.

LÉVY, Pierre. O que é o virtual. São Paulo. Ed. 34. 1996.

LÉVY, Pierre. Cibercultura. 3. ed. São Paulo: Editora 34, 2010.

MARINHO, Inezil Penna. História geral da educação física. 2. ed. São Paulo: Cia. Brasil Editora, 1980.

MERLEAU-PONTY, Maurice. Fenomenologia da percepção. 2. ed. São Paulo: Martins Fontes, 1999.

MUNHOZ, Angélica Vier; AQUINO, Julio Groppa. Inventariando o corpo na pesquisa educacional: sobre a constituição de um arquivo proliferante. Currículo sem Fronteiras, v. 20, n. 1, p. 313-331, jan./abr. 2020. Disponível em: https://www.curriculosemfronteiras.org/vol20iss1articles/munhoz-aquino.pdf. Acesso em: 22 fev. 2021.

NEUENFELDT, Derli Juliano; NEUENFELDT, Adriano Edo; SCHUCK, Rogério José; GOTTARDI, Eduardo; SCHONFFELDT; Sofia Daniela Giacobbo. A experiência da docência virtualizada no Ensino Superior no período da pandemia de COVID-19. SIMPÓSIO NACIONAL DE ESTRATÉGIAS E MULTIDEBATES DA EDUCAÇÃO - SABEREM QUE EDUCAM, 1,. 2020. Anais [...]. São Luís. p. 154-159, 2020. Disponível em: http://https://www.even3.com.br/isemeduc. Acesso em: 2 mar. 2021.

OLIVEIRA, Êmila Silveira. Motivação no Ensino Superior: estratégias e desafios. Contexto \& Educação, ljuí, a. 32, n. 101, p. 212-231, jan./abr. 2017. Disponível em: https://www.revistas.unijui.edu.br/index.php/ contextoeducacao/article/view/5924. Acesso em: 28 jul. 2021.

OLIVEIRA, Erik Cunha de; SANTOS, Vera Maria dos. Adoecimento mental docente em tempos de pandemia. Brazilian Journal of Development, Curitiba, v. 7, n. 4, p. 39.193-39.199, apr. 2021. Disponível em: https://doi.org/10.34117/bjdv7n4-399. Acesso em: 22 dez. 2021.

ORLANDI, Eni Puccinelli. Análise de discurso: princípios e procedimentos. 13. ed. Campinas, SP: Pontes, 2020.

SANTIN, Silvino. Em busca da filosofia do corpo. In: SANTIN, Silvino. Educação física outros caminhos. 2. ed. Porto Alegre: EST; ESEF, 1993. p. 47-65.

SANTIN, Silvino. Educação física, ética, estética, saúde. Porto Alegre: EST, 1995. 
SANTINELLO, Jamile; COSTA, Maria Luisa Furlan; SANTOS, Renata Oliveira dos. A virtualização do Ensino Superior: reflexões sobre políticas públicas e educação híbrida. Educar em Revista, Curitiba, v. 36, p. 1-20, 2020. Disponível em: https://www.scielo.br/scielo.php?script=sci_arttext\&pid=S0104-40602020000100603. Acesso em: 24 fev. 2021.

SANTOS, Boaventura de Sousa. A cruel pedagogia do vírus. Coimbra: Edições Almedina, 2020.

SERRES, Michel. Os cinco sentidos. Rio de Janeiro: Bertrand Brasil, 2001.

SERRES, Michel. Variações sobre o corpo. Rio de Janeiro: Bertrand Brasil, 2004.

SOARES, Carmen. Imagens da educação no corpo: estudo a partir da ginástica francesa no século XIX. Campinas: SP: Autores Associados, 1998.

SOUZA, Jeane Barros; HEIDEMANN, Ivonete Teresinha Schülter Buss; BITENCOURT, Julia Valeria Oliveira Vargas; AGUIAR, Denise Consuelo Moser; VENDRUSCOLO, Carine; VITALLE, Maria Sylvia Souza. Enfrentamento da Covid-19 e as possibilidades para promover a saúde: diálogos com professores. Revista de Enfermagem, Santa Maria, v. 11, e 12, p. 1-24, 2021. Disponível em: https://periodicos.ufsm.br/reufsm/ article/view/61363. Acesso em: 29 jul. 2021.

VEIGA-NETO, Alfredo. Anotações sobre as relações entre teoria e prática. Revista Educação em Foco, Juiz de Fora, v. 20, n. 1, p. 113-140, mar./jun. 2015. Disponível em: https://periodicos.ufff.br/index.php/edufoco/article/view/19627. Acesso em: 2 fev. 2021. 